\title{
Pengujian Orifice Flow Meter dengan Kapasitas Aliran Rendah
}

\author{
Ainul Ghurri, S.P.G. Gunawan Tista, Syamsudin \\ Jurusan Teknik Mesin Universitas Udayana, Kampus Bukit Jimbaran Bali 80362 \\ Telp.: +62 8123965206, Fax.: 361703321 \\ E-mail: a_ghurri@unud.ac.id
}

\begin{abstract}
Orifice flow meter is used in many laboratory and industrial application due because of its simple design and low cost. The present research investigated an orifice flow meter operated in relatively low flow rate. Orifice plate is a metal plate, $10 \mathrm{~mm}$ width provided with bevel at inlet section. The diameter ratios $(\beta)$ are $0.3,0.4,0.5$, $0.6,0.7$, and 0.8 , respectively. The experiment used water with flowrate range having Reynolds number between 6827,55 and 8004,72. The fluid is flown through the orifice plate. Pressure taps are used to measure pressure at upstream and downstream of the orifice plate. The actual capacity is directly measured at an outlet reservoir; while the theoretical capacity is calculated using modified Bernoulli equation with diameter ratio $(\beta)$ within the equation. The results showed that the irrecoverable pressure drop decreased with the increase of flow capacity and the diameter ratio. The discharge coefficient of the orifice flowmeter ranged between 0.3 and 1.3.
\end{abstract}

Keywords: Orifice flow meter, diameter ratio, pressure drop.

\section{PENDAHULUAN}

Orifice plate flow meter merupakan salah satu flowmeter berbasis beda tekanan (pressure differential) yang sangat banyak digunakan karena desain dan cara pengukurannya yang sederhana. Pengukuran aliran dibutuhkan dalam berbagai aplikasi antara lain untuk mengetahui konsumsi air rumah tangga, gedung komersial dan industri yang mengindikasikan kapasitas aliran pada stasiun pengisian bahan bakar, mengindikasikan kapasitas gas buang, dalam bidang kesehatan digunakan untuk memonitor pernafasan selama pembiusan dan mengukur kapasitas paru-paru. Kapasitas aliran dapat diukur dengan berbagai macam cara. Salah satunya adalah pengukuran aliran berbasis beda tekanan, dimana kapasitas aliran dihitung berdasar beda tekanan antara dua titik setelah melintasi sebuah penghalang yang dipasang untuk menimbulkan beda tekanan tersebut. Penurunan tekanan tersebut akan dipulihkan pada jarak tertentu pada arah hilir, namun tidak bisa dipulihkan secara keseluruhan. Penurunan tekanan yang tidak bisa dipulihkan tersebut disebut irrecoverable pressure drop atau permanent pressure drop. Beda tekanan melintasi penghalang tersebut harus cukup besar supaya bisa terukur dan sebaliknya harus cukup kecil agar permanent pressure drop yang terjadi memenuhi allowable pressure drop pada sistem dimana flow meter dipasang.

Dalam hal ini maka ada beberapa permasalahan yang akan dikaji, yaitu:

1. Bagaimana pengaruh posisi pengukuran beda tekanan terhadap distribusi tekanan sepanjang aliran pada kapasitas aliran rendah.
2. Bagaimana pengaruh posisi pengukuran beda tekanan terhadap variasi nilai discharge coefficient pada kapasitas aliran rendah.

3. Bagaimana pengaruh posisi pengukuran beda tekanan terhadap non recoverable pressure drop yang terjadi pada kapasitas aliran rendah.

4. Bagaimana karakteristik coefficient of discharge pada kapasitas aliran rendah.

Beberapa batasan ditetapkan dalam penelitian ini meliputi:

1. Tebal plat $10 \mathrm{~mm}$

2. Rasio diameter orifice dengan diameter pipa $(\beta)$ adalah $0.3 ; 0.4 ; 0.5 ; 0.6 ; 0.7 ; 0.8$.

3. Bilangan Reynolds bervariasi berdasarkan kapasitas alirannya.

4. Fluida yang digunakan adalah air.

\section{DASAR TEORI}

Pada peralatan pengukur aliran berbasis perbedaan (penurunan) tekanan, aliran dihitung dengan mengukur pressure drop yang terjadi pada aliran yang melewati sebuah penghalang yang dipasang dalam aliran tersebut. Flowmeter berbasis perbedaan tekanan ini didasarkan pada persamaan Bernoulli dimana sinyal yang terukur (yaitu penurunan tekanan) merupakan fungsi dari kuadrat kecepatan aliran. Dengan menggunakan orifice plate, aliran fluida diukur melalui perbedaan tekanan antara sisi hulu aliran sampai sisi hilir dimana di bagian tengah antara hulu dan hilir terdapat penghalang berbentuk orifice yang mengakibatkan aliran menjadi lebih sempit sehingga mengarahkan aliran untuk menyempit atau memusat.

Jika aliran mengalir horizontal (dengan 
demikian perbedaan elevasi tidak ada atau diabaikan) dan abaikan losses aliran yang terjadi; persamaan Bernoulli menjadi:

$$
\begin{array}{r}
P_{1}+\frac{1}{2} \rho v_{1}^{2}=P_{2}+\frac{1}{2} \rho v_{2}^{2} \\
P=\operatorname{Tekanan}(\mathrm{Pa}) \\
\rho=\operatorname{Densitas}\left(\mathrm{Kg} / \mathrm{m}^{3}\right) \\
v=\text { Kecepatan aliran }(\mathrm{m} / \mathrm{s})
\end{array}
$$

Untuk aliran vertikal ketinggian atau elevasi $h_{1}$ dan $\mathrm{h}_{2}$ harus dimasukkan dalam persamaan (1) di atas.

Asumsikan profil kecepatan aliran seragam pada sisi hulu dan hilir; maka persamaan kontinyuitas berlaku sebagai berikut:

$$
\begin{aligned}
q= & v_{1} A_{1}=v_{2} A_{2} \\
& q=\text { Laju alir volume atau kapasitas }\left(\mathrm{m}^{3} / \mathrm{s}\right)
\end{aligned}
$$

$A=$ Luas penampang aliran $\left(\mathrm{m}^{2}\right)$

Dengan mengkombinasikan (1) dan (2), $A_{2}<A_{l}$, menghasilkan persamaan 'ideal':

$$
q=A_{2}\left[\frac{2\left(P_{1}-P_{2}\right)}{\rho\left(1-\left(\frac{A_{2}}{A_{1}}\right)^{2}\right)}\right]^{1 / 2}\left(m^{3} / s\right)
$$

Untuk geometri tertentu (A), laju aliran dapat ditentukan dengan mengukur perbedaan tekanan $\mathrm{P}_{1}$ $\mathrm{P}_{2}$. Laju alir teoritis $\mathrm{q}$ dalam aplikasi praktis akan menjadi lebih kecil antara 2\% - 40\% akibat kondisi geometrinya. Persamaan ideal (3) dapat dimodifikasi dengan menambahkan discharge coefficient, menjadi:

$q=C d \cdot A_{2}\left[\frac{2\left(P_{1}-P_{2}\right)}{\rho\left(1-\left(\frac{A_{2}}{A_{1}}\right)^{2}\right)}\right]^{1 / 2}\left(m^{3} / \mathrm{s}\right)$

$$
C_{d}=\text { Discharge coefficient }
$$

Discharge coefficient $C_{d}$ merupakan fungsi bukaan orifice.

Berdasarkan persamaan Bernoulli dan kontinyuitas, kecepatan fluida akan mencapai nilai tertinggi dan tekanannya terendah pada vena contracta. Setelah melewati peralatan pengukur dan vena contracta akan terjadi penurunan kecepatan sampai pada level sebelum melewati penghalang. Vena contracta adalah luasan minimum yang terjadi pada bagian terdepan hilir aliran setelah penghalangan oleh orifice. Tekanan akan kembali naik namun lebih rendah dari tekanan sebelum melewati penghalang. Keadaan ini menambah head loss yang terjadi dalam aliran.

Persamaan (4) dapat dimodifikasi terhadap diameternya menjadi:

$$
\begin{array}{r}
q=C d \frac{\pi d^{2}}{4}\left[\frac{2\left(P_{1}-P_{2}\right)}{\rho\left(1-\beta^{4}\right)}\right]^{1 / 2}\left(m^{3} / s\right) \\
D=\text { Diameter dalam orifice }(\mathrm{m}) \\
d=\text { Diameter pipa hulu dan hilir (m) } \\
\beta=\text { Rasio diameter } d / D \\
\pi=3.14
\end{array}
$$

Persamaan (5) dapat dimodifikasi ke laju alir massa fluida dengan mengalikannya dengan densitas fluida.

$$
m=C d \frac{\pi d^{2}}{4} \rho\left[\frac{2\left(P_{1}-P_{2}\right)}{\rho\left(1-\beta^{4}\right)}\right]^{1 / 2}(K g / s)(6)
$$

Dalam pengukuran aliran gas, perlu diperhitungkan tidak hanya penurunan tekanan yang terjadi, tapi juga perubahan densitasnya. Persamaan di atas dapat digunakan untuk aplikasi dimana perubahan tekanan dan densitasnya relatif kecil. Adanya vena contracta saat melintasi orifice plate, maka persamaan $Q_{\text {orifice }}$ menjadi:

$$
Q_{\text {orifice }}=\frac{1}{\sqrt{1-\beta^{4}}} \frac{\pi d^{2}}{4} \sqrt{2 \rho \Delta P}(K g / s)
$$

Orifice meter terdiri dari plat orifice datar dengan lubang sirkular (lingkaran). Dua lubang tekanan dibuat masing-masing satu pada hulu dan hilir aliran. Secara umum ada 3 metode penempatan lubang tekanan (tap). Coefficient of discharge pengukuran tergantung pada posisi tap.

Salah satu cara membandingkan keakuratan alat ukur aliran berbasis pada tekanan adalah dengan membadingkan kapasitas aliran aktual terhadap kapasitas aliran teoritisnya. Rasio antara kapasitas aliran actual terhadap kapasitas aliran teoritis disebut coefficient of discharge $(C d)$ :

$C d=\frac{\text { Kapasitas aktual }}{\text { Kapasitas teoritis }}=\frac{Q_{\text {actual }}}{Q_{\text {theoriticd }}}$

\section{METODE PENELITIAN}

Penelitian dan pengujian orifice meter ini mempergunakan peralatan dan bahan sebagai berikut:

1. Meja

2. Tandon air (350 liter)

3. Keran Tandon

4. Bak air utama (24 liter)

5. Keran bak utama

6. Selang

7. Papan

8. Double tape

9. Penggaris

10. Kelem

11. Selang manometer

12. Orifis

13. Pipa orifis 
14. Penyangga set up orifice

15. Bak penampung debit (7 liter)

16. Stop watch

Gambar 2 dan 3 berturut-turut menunjukkan bagian uji orifice plate secara skematik dan gambar aktualnya. Sedangkan Gambar 4 menunjukkan peralatan pengujian secara lengkap.
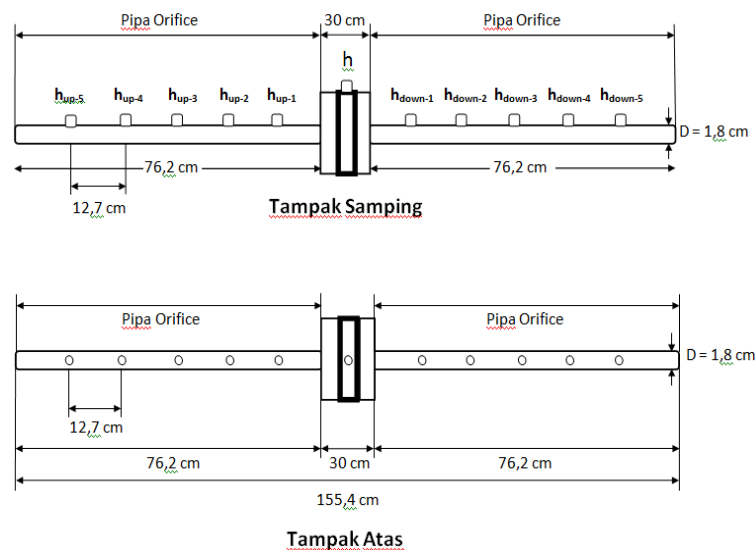

Gambar 2. Detail orifice plate

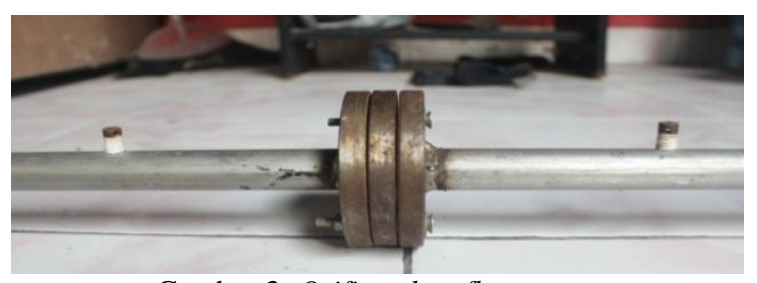

Gambar 3. Orifice plate flow meter

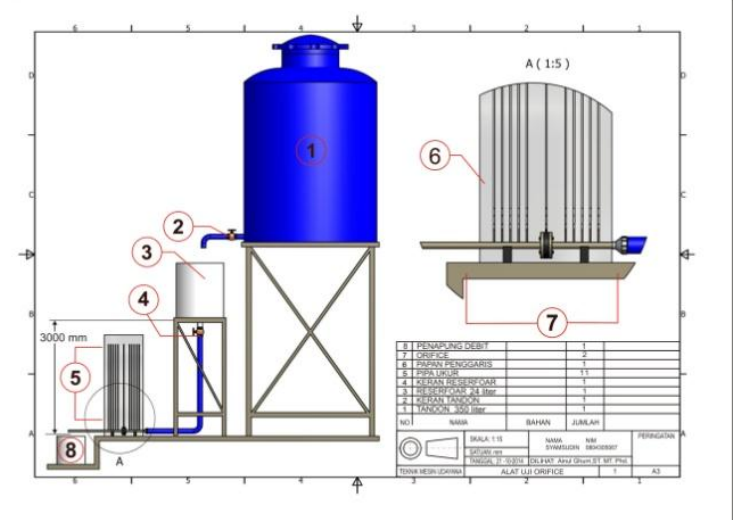

(a) Skematik

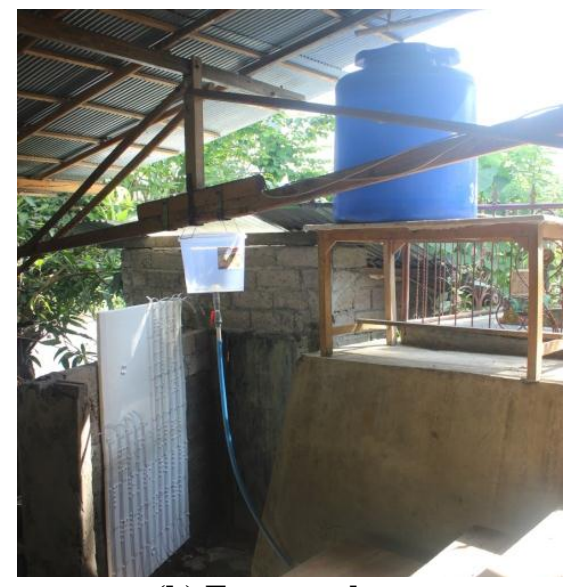

(b) Foto peralatan

Gambar 4. (a) dan (b) Set Up eksperimental orifice flowmeter

Keterangan:

1. Tandon air 350 ltr

2. Keran tandon

3. Bak air utama (reserfoar 24 ltr)

4. Keran Bak air utama (reserfoar 24 ltr)

5. Selang ukur (manometer)

6. Papan ukur (papan manometer)

7. Set up orifice

8. Penampung debit.

\section{HASIL DAN PEMBAHASAN}

\section{Distribusi tekanan sepanjang orifice flow meter}

Dari hasil pengujian maka didapatkan distribusi tekanan sepanjang aliran dengan rasio diameter $(\beta)$ 0.3 ; $0.4 ; 0.5 ; 0.6$; 0.7 ; dan 0.8 seperti pada grafikgrafik di bawah ini.

Adapun distribusi tekanan setiap rasio diameter ( $\beta$ ) pada kapasitas aktualnya dapat dilihat pada grafik dibawah ini:

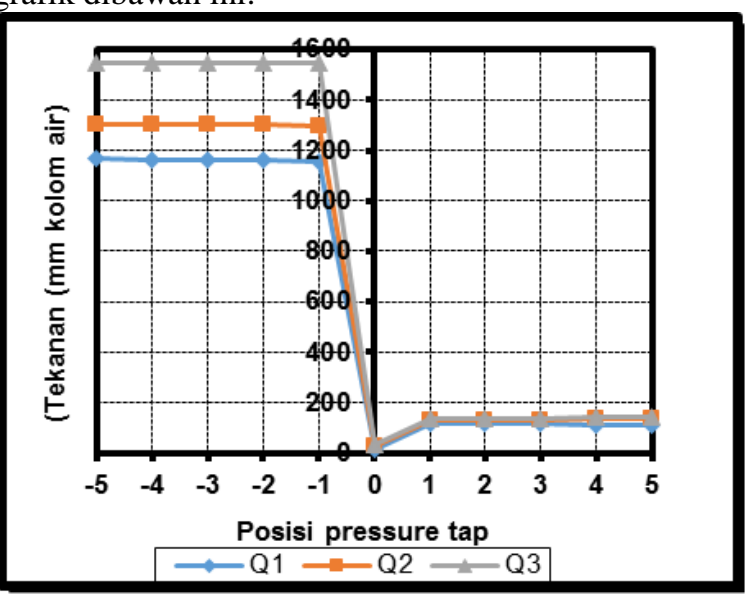

Gambar 5. Grafik distribusi tekanan untuk d = 5,4 mm 


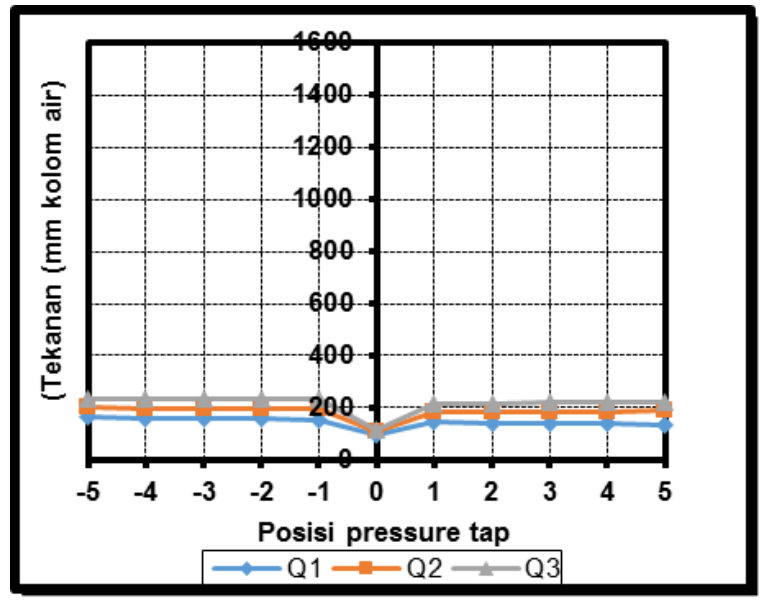

Gambar 6. Grafik distribusi tekanan, $\mathrm{d}=14,4 \mathrm{~mm}$

Dari 2 gambar grafik distribusi tekanan diatas dapat disimpulkan bahwa semakin besar $\beta$ atau diameter orifis maka semakin kecil terjadinya penurunan tekanan.

\section{Kapasitas Teoritis}

Berdasarkan kapasitas aktual pada bak penampung output dan diameter pipa $(\mathrm{D}=18 \mathrm{~mm})$, maka dapat dihitung kecepatan air keluar dari pipa hilir sehingga dapat dicari bilangan reynolds untuk tiap kapasitas aktualnya, Menurut Streeter (1975) viskositas kinematik air $20^{\circ} \mathrm{c}$ sebesar $1.007 \times 10^{-6}$. Untuk aliran laminar dan turbulen, dapat digunakan bilangan Reynolds $\left(R_{e}\right)$ sebagai acuan untuk

Pressure drop dapat dicari dengan rumus :

Dimana :

$$
\Delta P=-\rho \cdot g(\Delta h)
$$

$$
\begin{aligned}
& \rho=\text { densitas air }\left(\frac{\mathrm{kg}}{\mathrm{m}^{3}}\right) \\
& g=\operatorname{gravitasi}\left(\frac{\mathrm{s}}{\mathrm{s}^{2}}\right) \\
& \Delta h=\left(h_{\text {down }}-h_{\text {up }-1}\right)
\end{aligned}
$$

Dengan menghitung pressure drop maka kapasitas aliran secara teoritis dapat dihitung dengan menggunakan rumus :

$$
\begin{gathered}
Q_{\text {teoritis }}=\frac{1}{\sqrt{1-\beta^{4}}} \frac{\pi d^{2}}{4} \sqrt{2 \rho \Delta P}(\mathrm{~kg} / \mathrm{s}) \\
Q_{\text {teoritis }}=\frac{1}{\sqrt{1-\beta^{4}}} \frac{\pi d^{2}}{4} \sqrt{2 \rho \Delta P} \frac{1}{\rho}\left(\mathrm{m}^{3} / \mathrm{s}\right)
\end{gathered}
$$

Adapun nilai dari kapasitas teoritis yang sudah dihitung dapat diplotkan pada grafik hubungan antara kapasitas terhadap bilangan Reynolds seperti yang terlihat dibawah ini :

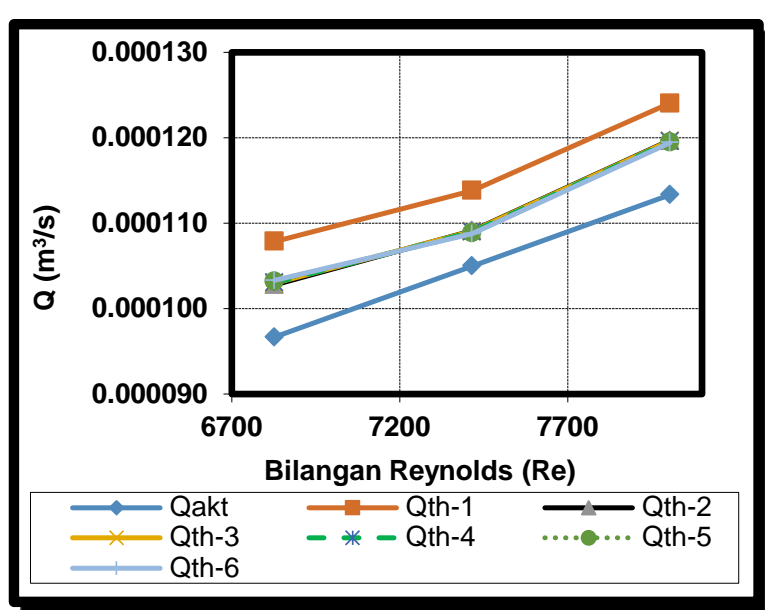

Gambar 7. Grafik $Q_{\text {theoritis }}$ terhadap Re untuk $\mathrm{d}=5,4 \mathrm{~mm}$

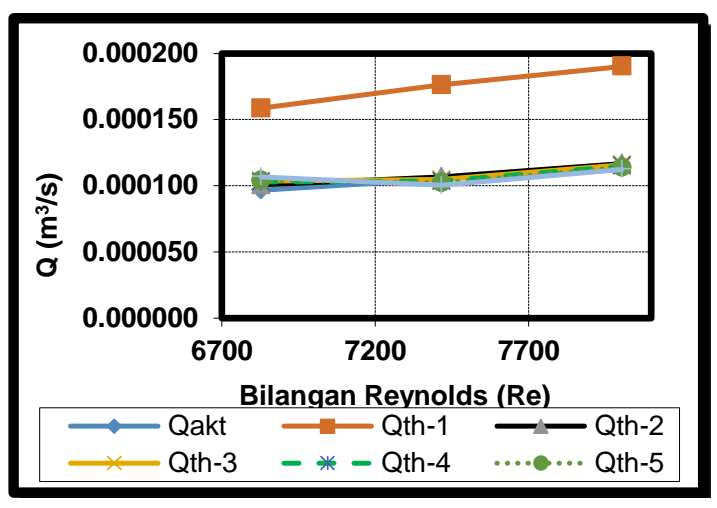

Gambar 8. Grafik $Q_{\text {theoritis }}$ terhadap Re untuk $\mathrm{d}=10,8 \mathrm{~mm}$

Dari kedua rumus diatas dapat disimpulkan bahwa semakin besar nilai $\Delta \mathrm{P}$ yang didapat maka semakin besar nilai dari kapasitas teoritisnya. Semakin besarnya nilai dari kapasitas teoritis maka semakin besar niali bilangan Reynolds-nya.

\section{Coefficient of discharge}

Dari nilai $Q_{\text {th }}$ yang menggunakan letak pengukuran beda tekanan antara pressure tap pada hulu dan pada plat orifice maka nilai $\mathrm{Cd}$ dapat dihitung dengan menggunakan rumus:

$$
C_{d}=\frac{Q_{a c t}(\text { liter } / \text { menit })}{Q_{t h}(\text { liter } / \text { menit })}
$$

Adapun nilai Cd yang dapat diplotkan pada grafik seperti yang terlihat dibwah ini: 


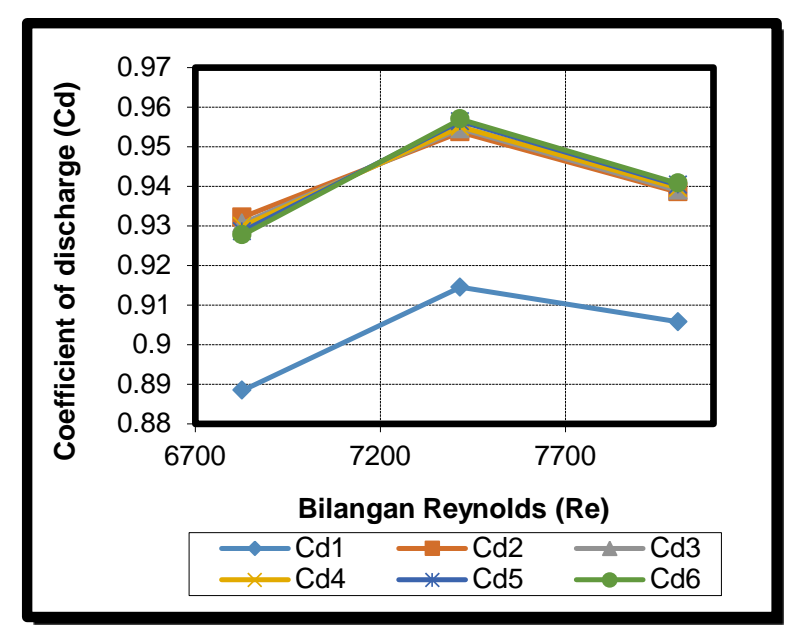

Gambar 9. Grafik $C d$ terhadap Re untuk d = 5,4 mm

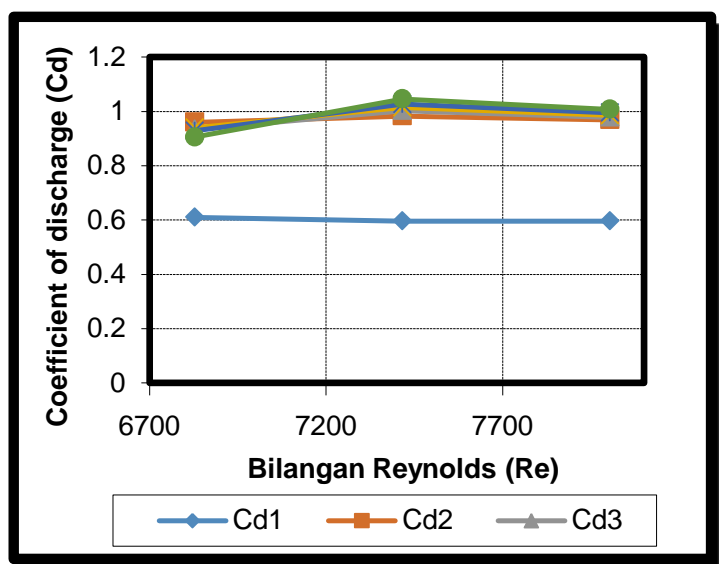

Gambar 10. Grafik $C d$ terhadap Re untuk $\mathrm{d}=10,8 \mathrm{~mm}$

Ada 2 hal yang dapat disimpulkan dari kedua grafik diatas yaitu semakin besar diameter orifis maka semakin besar nilai $\mathrm{Cd}$ dan hanya pada $\mathrm{Cd}_{1}$ dan $\mathrm{Cd}_{2}$ yang sesuai dengan semakin besar bilangan Reynolds maka nilai Cd semakin turun atau kecil.

Nilai Cd (coefficient discharge) untuk orifice flow meter nilainya berkisar 0,3535 - 1,3374 dimana nilai $\mathrm{Cd}$ terendah ada pada $\mathrm{d}=14,4 \mathrm{~mm}$ di posisi pressure tap $\mathrm{h}_{\text {down-1 }}$, sedangkan nilai Cd tertinggi pada posisi pressure tap $\mathrm{h}_{\text {down-5. }}$. Berdasarkan nilai $\mathrm{Cd}$ letak pressure tap yang baik berada pada $\mathrm{h}_{\text {down-2 }}$ dengan nilai $\mathrm{Cd}=1,0073$ pada $\mathrm{d}=14,4 \mathrm{~mm}\left(\mathrm{Q}_{\text {aktual }}=6,3\right.$ ltr/mnt).

\section{Pressure Drop dan Irrecoverable Pressure Drop}

Presentase dari Irrecoverable pressure drop dapat dicari dengan menggunakan rumus :

$$
\text { Irrecoverable pressure drop }=\frac{\Delta \mathrm{P}_{\max }}{\Delta \mathrm{P}_{\mathrm{irre}}} x 100 \%
$$

Dengan mendapatkan nilai prosentase Irrecoverable pressure drop sehingga dapat diplotkan pada grafik Gambar 11 dan 12.

Dari dua grafik tersebut ada beberapa yang dapat disimpulkan yaitu semakin besar diameter orifis maka semakin kecil nilai dari pressure drop max, dan juga irrecoverable pressure drop-nya.

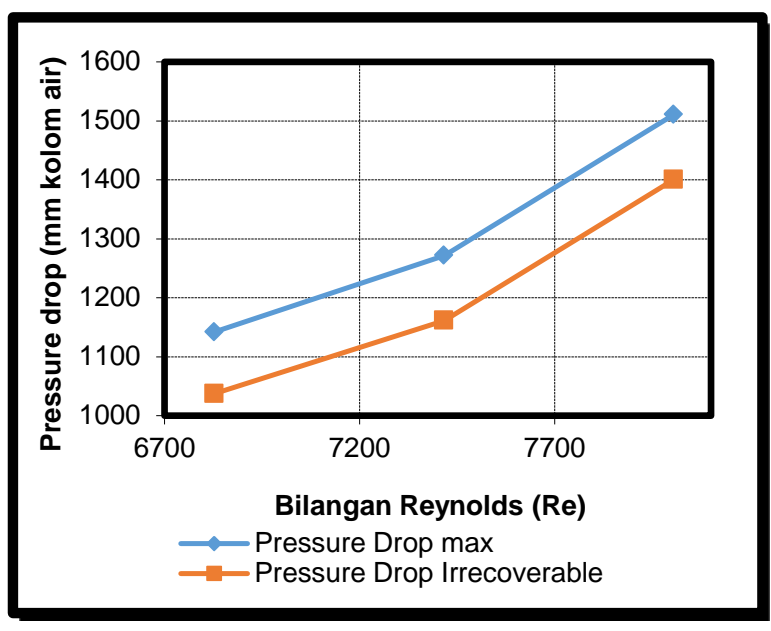

Gambar 11. Grafik hubungan antara pressure drop terhadap Re untuk d = 5,4 $\mathrm{mm}$

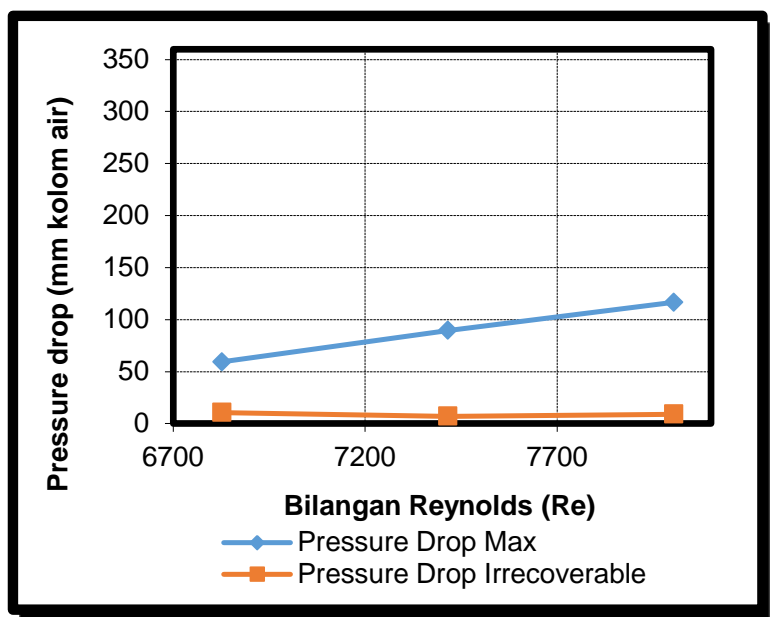

Gambar 12. Grafik hubungan antara pressure drop terhadap Re untuk d = 14,4 mm

\section{KESIMPULAN}

Berdasarkan hasil pembahasan dari penelitian mengenai orifice flow meter dengan $(\beta)=0.3 ; 0.4$; $0.5 ; 0.6 ; 0.7$; dan 0.8 dapat disimpulkan beberapa hal antara lain:

1. Perhitungan kapasitas teoritis yang menggunakan beda tekanan $(\Delta \mathrm{P})$ pada posisi $\left(\mathrm{h}_{\text {down-1 }}-\mathrm{h}_{\mathrm{up}-1}\right)$ titik pada plat orifice 
menghasilkan kapasitas teoritis yang paling mendekati kapasitas aktual yang terukur.

2. Nilai $\mathrm{Cd}$ (coefficient discharge) untuk orifice flow meter nilainya berkisar 0,3535 - 1,3374 dimana nilai $\mathrm{Cd}$ terendah ada pada $\mathrm{d}=14,4 \mathrm{~mm}$ di posisi pressure tap $h_{\text {down-1 }}$, sedangkan nilai $C d$ tertinggi pada posisi pressure tap $\mathrm{h}_{\text {down-5 }}$.

3. Berdasarkan nilai $\mathrm{Cd}$ letak pressure tap yang baik berada pada $\mathrm{h}_{\text {down-2 }}$ dengan nilai $\mathrm{Cd}=$ 1,0073 pada $\mathrm{d}=14,4 \mathrm{~mm}\left(\mathrm{Q}_{\text {aktual }}=6,3 \mathrm{ltr} / \mathrm{mnt}\right)$.

4. Semakin besar diameter orifis maka semakin kecil terjadinya pressure drop dan irrecoverable pressure drop-nya.

\section{UCAPAN TERIMA KASIH}

Penelitian ini merupakan bagian dari Penelitian Hibah Bersaing 2015. Penulis menyampaikan ucapan terima kasih kepada Kementerian Ristek Dikti dan LPPM atas pembiayaan pelaksanaan penelitian ini.

\section{DAFTAR PUSTAKA}

[1] Gunarsa. Gede, 2006 "Pengujian Nozzle Flow Meter dengan Variasi Rasio Diameter Nozzle".

[2] Krassow. H., Campabadal. F., Lora-Tamayo. E., 1998 "The Smart Orifice Meter; a Mini Head Meter for Volume Flow Measurement". 1998, 110.

[3] Munson, Bruce. R., Young, Donald. F., Okiishi, Theodore. H., 2002 "Fundamental of Fluid Mechanic", $4^{\text {th }}$ Edition, John Wiley \& Sons, USA.

[4] R. W. Miller, 1989 "Flow Measurement Engineering Handbook, second ed., McGraw Hill Publishing Company, New York, pp- 7-17-8.

[5] Septiadi. Nata, 2006 "Studi Eksperimen Orifice Flow Meter dengan Variasi Tebal Plat Orifis dan Posisi Pengukuran Beda Tekanan Aliran Melintasi Plat Orifis".

[6] W. Fox, Robert., T. McDonald., Alan, 1994 "Introduction to Fluid Mechanic". 1994, 360363. 